\title{
PERUBAHAN RUANG BERBASIS TRADISI RUMAH JAWA PANARAGAN DI DESA KAPONAN
}

\author{
Yunita Nurmayanti \\ Mahasiswa Magister Arsitektur Lingkungan Binaan Universitas Brawijaya dan Staf Dinas \\ Lingkungan Hidup Kota Batu \\ E-mail: yunitanurmamira@gmail.com
}

Lisa Dwi Wulandari

Dosen Magister Arsitektur Lingkungan Binaan Universitas Brawijaya

E-mail: lisaromansya@yahoo.co.uk

\section{Agung Murti Nugroho}

Dosen Magister Arsitektur Lingkungan Binaan Universitas Brawijaya

E-mail: sasimurti@yahoo.co.id

\begin{abstract}
Abstrak
Tatanan spasial (ruang) memperlihatkan hubungan antara arsitektur dan budaya masyarakat setempat. Manusia sebagai makhluk yang berpikir dinamis, memiliki peran besar untuk merubah lingkungan fisik maupun kebudayaan. Tatanan ruang tradisional merupakan warisan leluhur yang harmonis, senantiasa mengalami perubahan untuk beradaptasi dengan modernitas budaya global. Penelitian ini bertujuan untuk (1) mengidentifikasi dan menganalisis unsur-unsur ruang yang berubah dan (2) menjelaskan faktor-faktor sosial-budaya yang mempengaruhinya, pada objek rumah tinggal tradisional di wilayah kebudayaan Jawa Panaragan. Objek penelitian berupa rumah-rumah berlanggam arsitektur Jawa, yang telah berdiri sejak sebelum era kemerdekaan RI, terletak di wilayah tertua dari permukiman Desa Kaponan. Metodologi penelitian menggunakan pendekatan kualitatif-rasionalistik dengan analisis deskriptif. Penggalian data melalui observasi langsung terhadap objek yang menjadi kasus penelitian dan wawancara silang dengan informan (narasumber dan keyperson) terkait. Variabel penelitian meliputi organisasi, fungsi, hirarki, orientasi serta teritori ruang sebagai panduan untuk mengamati perubahan ruang dalam 2 (dua) periode waktu. Objek/kasus penelitian dipilih secara sengaja berdasar kriteria meliputi rumah lurah, carik, pamong desa dan tokoh masyarakat yang menjabat pada masa lampau, dilengkapi dengan rumah petani serta buruh tani. Hasil penelitian menunjukkan bahwa unsur spasial (ruang) yang banyak berubah adalah organisasi dan teritori ruang sebagai konsekuensi dari penambahan jumlah, jenis dan fungsi ruang. Unsur spasial yang sedikit berubah adalah orientasi dan hirarki ruang karena kuatnya faktor kepercayaan leluhur. Faktor yang mempengaruhi terjadinya perubahan ruang terutama adalah struktur keluarga dan perubahan gaya hidup seiring meningkatnya pengetahuan dan pendidikan.
\end{abstract}

Kata-kata kunci : perubahan ruang, rumah tradisional, Jawa Panaragan 


\title{
THE TRADITION BASED ROOM CHANGES IN JAWA PANARAGAN HOUSE OF KAPONAN VILLAGE
}

\begin{abstract}
Spatial order (space) shows the relationship between the architecture and the culture of local community. As dynamic thinking creature, human has a major role in changing the physical environment or culture. Order of the traditional spaces which is a harmonious ancestral heritage is constantly changing to adapt to the global culture of modernity. This research aimed to (1) identify and analyze the elements of spatial change and (2) explain the socio-cultural factors that affected it, on the object of traditional house in the Panaragan Javanese cultural area. The object of research were traditional Javanese type of home, built before the era of Indonesia independence (1945), located in the oldest settlement of the Kaponan Village. The research methodology used a qualitative-rationalistic approaches with descriptive analysis. Data mining was conducted through direct observation of objects that became case studies and interviews with related informants and keyperson. Variables of research include organization, function, hierarchy, orientation and territory of spatial (space) as a guide for observing spatial change between two periods of time. Object/case studies were deliberately chosen based on criteria include the house of the village head and officials, teacher and community leaders who served in the past, also added with home of farmers and farmworkers. The results showed that elements of the spatial (space) which was much changed was the organization and territorial spaces as a consequence of the addition of the number, type and function space. The elements of spatial orientation and space hierarchy was less changed, because of the strong ancestral belief and religion. The main factors affecting the occurrence of a spatial change was family structure and lifestyle changes, along with the increasing knowledge and education.
\end{abstract}

Keywords: change spaces, traditional house, Jawa Panaragan

\section{Pendahuluan}

Globalisasi membawa manfaat positif, seperti kemajuan teknologi dan kelancaran arus informasi, sekaligus menimbulkan problematika. Modernitas pada era globalisasi dikhawatirkan dapat menggusur budaya lokal, seperti objek-objek arsitektur tradisional di Pulau Jawa yang mulai kehilangan identitasnya. Upaya preventif, dilakukan melalui penelitian untuk menggali kearifan lokal dari arsitektur nusantara. Arsitektur sebagai wujud kebudayaan yang paling konkret, mudah diamati perubahannya. Perubahan ruang amat menarik untuk dicermati, karena sifat masyarakat tradisional yang lekat dengan tatanan kehidupan kolektif, senantiasa mengalami transisi. Keterbukaan terhadap budaya global diharapkan mampu memadu-padankan modernitas dengan unsur-unsur tradisional warisan leluhur, sehingga arsitektur di wilayah budaya Jawa Panaragan dapat terjaga kelestarian dan kontinuitas tradisinya serta bisa diteruskan pada konteks masa kini dan waktu yang akan datang.

Tradisi berasal dari kata Latin "tradere", mempunyai makna sebagai "mewariskan sesuatu yang bernilai luhur", baik berbentuk fisik, seperti "produk arsitektural" maupun bersifat non fisik, yakni "adat-istiadat" (Susilo, 2010). Kajian terhadap objek arsitektural kuno dan adat-istiadat yang melatar-belakangi, diharapkan dapat menjadi sumber pengetahuan maupun solusi bagi masalahmasalah penataan lingkungan binaan dewasa ini, saat dunia kehilangan sekat batas antar negara dan kebudayaan.

Jawa Panaragan merupakan salah satu dari sepuluh wilayah kebudayaan Jawa Timur, selain Jawa Mataraman, Arek, Samin/Sedulur Sikep, Tengger, Osing/Using, Pandalungan, Madura Pulau, 
Madura Bawean, dan Madura Kangean (Sutarto, 2004). Tipe rumah tradisional di wilayah budaya Jawa Panaragan dikenal berdasarkan bentuk atapnya. Bentuk atap yang mendominasi fasade rumah tradisional tersebut, adalah bucu, sinom, dorogepak dan srotongan menurut Setiawan dalam (Kartono, 2005) dan (Susilo, 2015), seperti Gambar 1. Rumah Jawa Panaragan minimal terdiri atas 3 (tiga) gugusan massa bangunan berdasarkan fungsinya, yaitu griya ngajeng, griya wingking dan pawon-sumur (Susilo, 2015). Ruang pada rumah Jawa Panaragan meliputi ruang dalam, ruang antara dan ruang luar yang terdiri atas halaman-halaman (latar ngarep, latar mburi, latar wetan dan latar kulon), untuk mewadahi aktivitas kehidupan sehari-hari pada masyarakat pedesaan yang agraris, seperti Gambar 1.

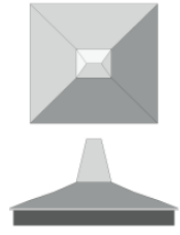

BUCU
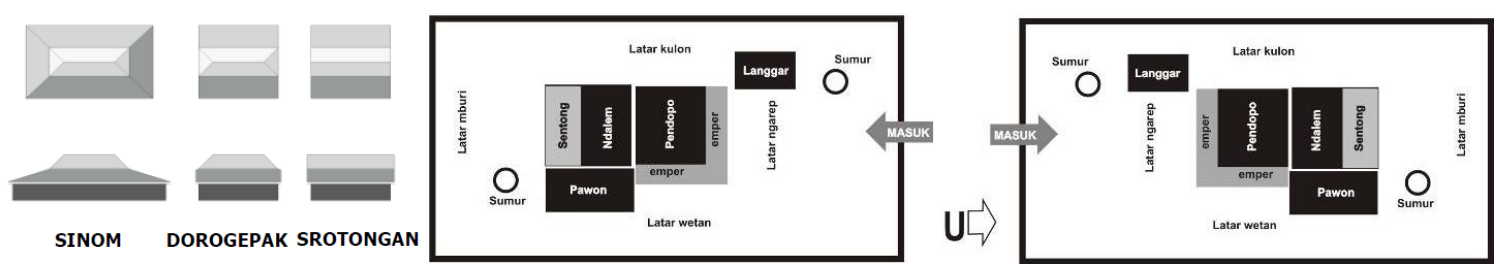

Gambar 1. Tipe dan pola ruang rumah di wilayah budaya Jawa Panaragan Sumber: Susilo, 2015 dan 2010

Masyarakat Jawa Panaragan terkenal dengan ciri-ciri, yaitu sangat menghormati tokoh-tokoh formal yang mereka kenal sebagai pangreh praja. Tokoh-tokoh seperti warok dan ulama juga menjadi panutan dalam kehidupan masyarakat (Sutarto \& Sudikan, 2004). Bertolak dari ciri-ciri tersebut, maka objek penelitian adalah rumah milik Lurah, Carik, Pamong Desa dan tokoh masyarakat yang menjabat pada masa lalu, dihuni serta dipelihara oleh ahli waris generasi ke-2 maupun ke-3 kini, sehingga dapat diamati perubahan ruangnya berdasarkan tradisi fisik (arsitektural) dan non fisik (adat-istiadat) yang masih berlanjut (Gambar 2). Objek penelitian terletak di permukiman tertua Desa Kaponan, Kabupaten Ponorogo.

Adat-istiadat yang menjadi ciri-khas masyarakat Jawa Panaragan yang men-tradisi hingga kini, yaitu "Sejarah" dan "Becekan". "Sejarah" adalah tradisi untuk merayakan datangnya hari raya Idul Fitri dengan bersilaturahmi secara berkeliling dan berkelompok ke rumah-rumah sesepuh, tokoh masyarakat dan warga desa (Gambar 2). "Becekan" adalah tradisi mbecek dan rewang yang dilaksanakan saat hajatan pernikahan maupun sunatan.
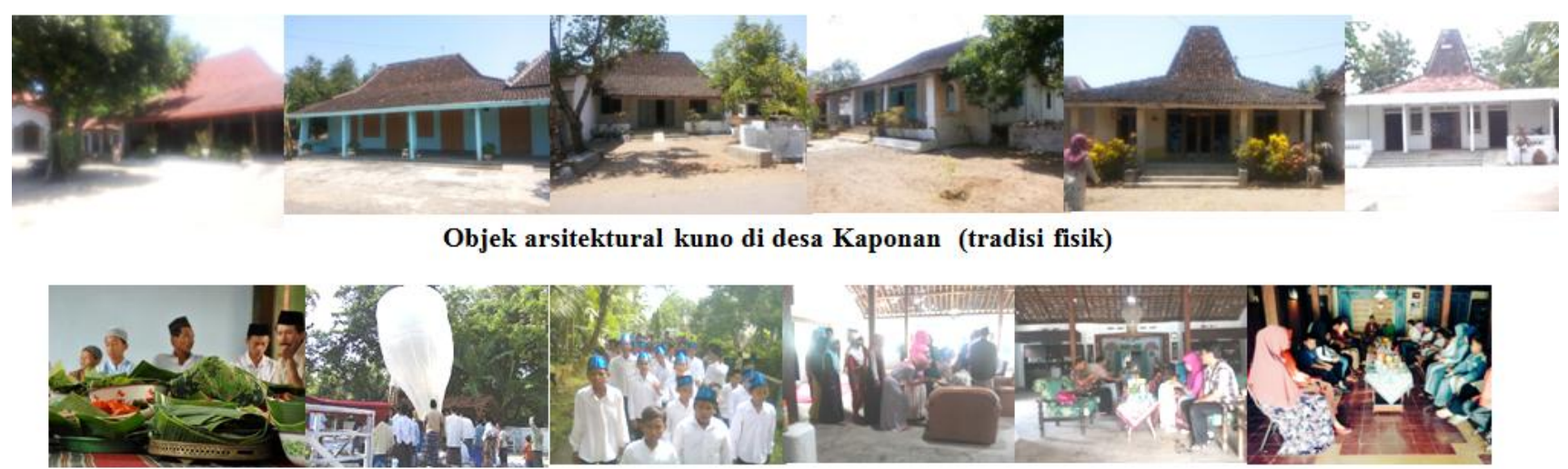

Adat-istiadat masyarakat Jawa Panaragan dalam menyambut Hari Raya Idul Fitri (tradisi non fisik)

Gambar 2. Objek arsitektural dan adat-istiadat masyarakat Jawa Panaragan yang mentradisi 
Sumber: dokumentasi, 2016

Manusia sebagai makhluk sosial yang berpikir dinamis, senantiasa berinteraksi dan beradaptasi dengan lingkungan sekitar melalui aktivitas-aktivitas yang memerlukan sistem spasial (ruang). Sistem spasial (ruang) sebagai salah satu tolak ukur fundamental yang stabil untuk melakukan kajian arsitektur, selain sistem fisik dan sistem stilistik, sementara itu, intervensi manusia sangat mempengaruhi perubahan ruang (Habraken, 1988). Interaksi antara sesama manusia dan lingkungan mengakibatkan adanya dinamika kebudayaan yang ikut berimbas pada dinamika ruang. Fenomena sosial-budaya merupakan faktor utama yang menentukan perwujudan serta perubahan arsitektur rumah tinggal, selain faktor visual (Rapoport, 2005).

Sistem spasial pada suatu rumah tinggal berkaitan dengan denah, mencakup organisasi ruang, orientasi serta hirarki ruang (Habraken: 1988). Aplikasi sistem spasial dalam keterkaitannya dengan man, space dan time menurut (Mannuel Marti Jr, 1983), dapat diklasifikasikan menjadi dua faktor, yakni struktur spasial (organisasi, hirarki, sirkulasi serta teritori ruang) dan nilai spasial (makna, fungsi dan pemanfaatan ruang). Aspek-aspek pada sistem spasial dapat diamati perubahannya melalui tiga indikator, yaitu penambahan, pengurangan dan pemindahan (Habraken, 1982) yang dapat mempengaruhi tata letak maupun teritori pemanfatan ruang.

Perubahan ruang pada rumah tradisional menurut (Altman \& Chemers, 1989), selain dipengaruhi oleh lingkungan (tanah, suhu dan iklim) serta teknologi (material dan keahlian tukang), juga terkait dengan faktor budaya. Faktor budaya tersebut meliputi tingkat privasi, kepercayaan dan nilai-nilai, struktur sosial dan struktur keluarga. Perubahan ruang sebagai keterkaitan antara desain lingkungan dan budaya juga dilatar-belakangi oleh pandangan hidup, tata nilai, pola image serta makna ideal yang merujuk pada gaya hidup/lifestyle (Rapoport, 2005).

\section{Metodologi}

Penelitian ini menggunakan metode kualitatif-rasionalistik dengan analisis deskriptif untuk membahas perubahan spasial (ruang) pada masa lalu (minimal 50 tahun yang lalu) dan sekarang, terdiri atas variabel organisasi, fungsi, hirarki, orientasi dan teritori ruang.

Obyek atau kasus penelitian berjumlah 10 (sepuluh), ditetapkan secara sengaja berdasarkan kriteria tertentu, yaitu rumah berusia lebih dari 50 tahun atau telah ditempati minimal oleh 2 generasi. Kriteria berikutnya, rumah bercirikan arsitektur tradisional Jawa Panaragan, dikenali berdasarkan bentuk atap bucu, sinom, dorogepak dan srotongan, dengan kondisi fisik yang terpelihara serta dihuni oleh ahli waris. Berdasarkan kriteria budaya masyarakat Jawa Panaragan yang menjadikan panutan para pangreh praja dan tokoh masyarakat, maka objek atau kasus penelitian terdiri atas rumah Lurah, Carik, Pamong Desa dan tokoh masyarakat yang menjabat pada masa lampau, dilengkapi dengan rumah petani serta buruh tani terpilih berdasarkan kriteria inklusi, yang mewakili situasi objek sejenis.

Tahapan penelitian melalui observasi langsung, wawancara silang dengan narasumber (pemilik-penghuni-ahli waris rumah) dan diskusi dengan keyperson (sesepuh-tokoh masyarakat) serta studi literatur terkait untuk memperoleh data fisik maupun faktor sosial budaya yang melatarbelakangi perubahan ruang. Identifikasi dan klasifikasi data sebagai bahan analisis berdasarkan indikator/variabel untuk menyusun laporan serta menarik kesimpulan mengenai perubahan ruang.

\section{Hasil dan Pembahasan}

\section{Gambaran Lokasi dan Sejarah}

Lokasi penelitian adalah Desa Kaponan yang terletak di Kecamatan Mlarak, Kabupaten Ponorogo, Kaponan merupakan tipologi desa persawahan dengan luas wilayah 334.235 Ha, jumlah penduduknya 2856 jiwa tersebar di 8 RW dan 19 RT. Terdiri atas 3 dusun, yaitu Kaponan I, 
Kaponan II dan Kaponan III. Kaponan juga terdiri atas beberapa dukuh yakni Krajan, Njeblog, Sendang, Puthuk Mojo, Prayungan, Kampung Baru, dan Ngledok. Permukiman di Desa Kaponan terbagi atas beberapa segmen wilayah, masing-masing dibatasi oleh lahan pertanian dan deretan pepohonan serta terhubung dengan jaringan jalan, sehingga terlihat membentuk kantong-kantong permukiman.

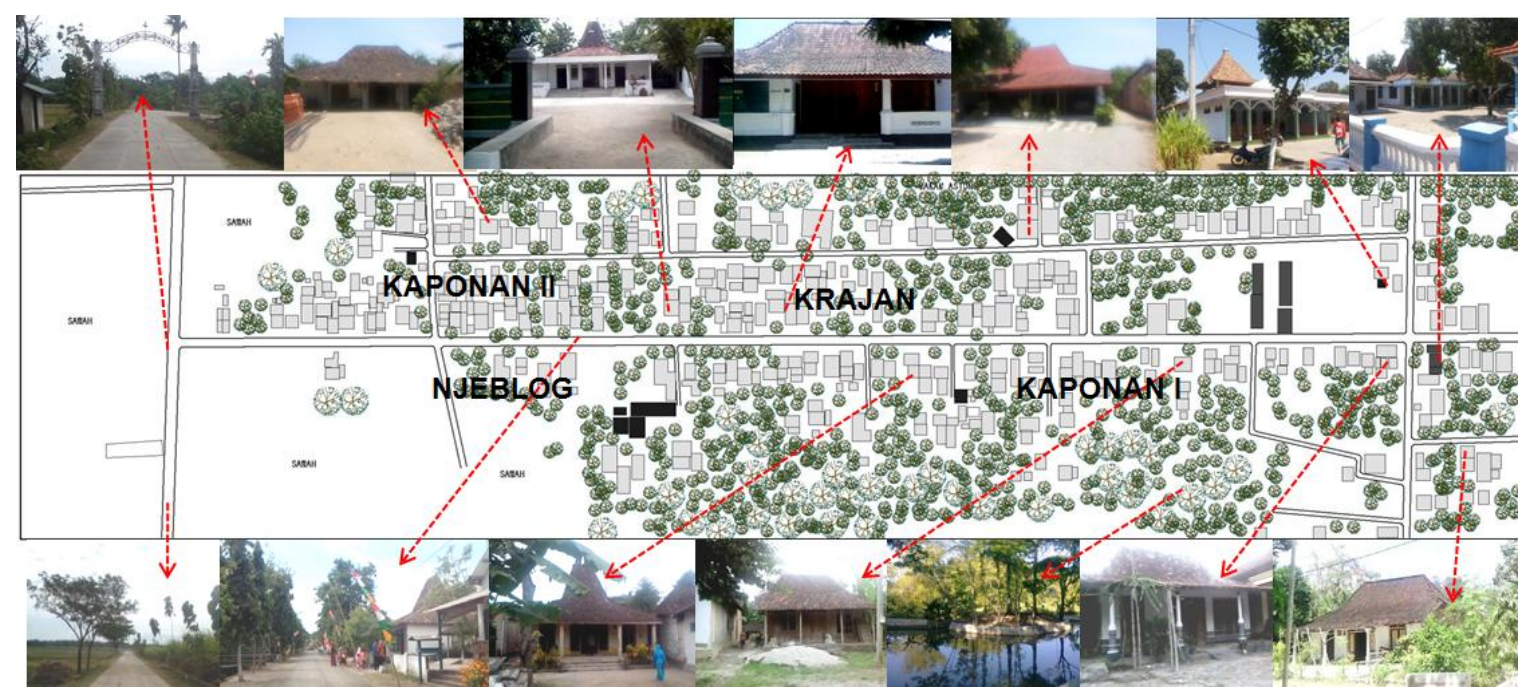

Gambar 3. Gambaran eksisting wilayah penelitian Sumber: hasil penelitian, 2016.

Wilayah penelitian ditetapkan dengan tujuan tertentu, agar lebih fokus dalam menjawab permasalahan. Wilayah penelitian merupakan permukiman tertua yang telah dibuka sejak tahun 1777 oleh R. Ng. Soetowijoyo dan Abdul Rosyid beserta para kerabat. Leluhur yang membuka Hutan Kaponan dan mendirikan cikal-bakal permukiman adalah anggota rombongan Pakubuwono II yang mengungsi karena peristiwa "geger pecinan" pada tahun 1742. Rombongan ini pernah ditampung oleh Kyai Ageng Muhammad Besari di Pesantren Gerbang Tinatar, Tegalsari Ponorogo dan setelah mendapat restu, berpencar ke berbagai wilayah untuk membuka hutan (Soegijono et al, 2006). Pada wilayah penelitian (Gambar 3), terdapat bukti fisik peninggalan Makam Astono, merupakan kantong permukiman terpadat dan terlengkap sarana-prasarananya, yang meliputi balai desa, mesjid, musholla, madrasah, sekolah dasar dan sawah bengkok. Sarana sumber air, jalan utama dan lapangan desa, menjadi pusat berlangsungnya upacara-upacara terkait tradisi budaya pada masa lampau maupun zaman sekarang.

Objek penelitian terdapat pada wilayah terpilih, yaitu rumah-rumah berlanggam tradisional Jawa milik Lurah, Carik, pamong desa dan tokoh-tokoh masyarakat yang menjabat pada masa lampau. Pemilik objek penelitian merupakan kerabat atau memiliki garis keturunan langsung dengan leluhur pendiri desa. Beberapa objek penelitian merupakan rumah-rumah tua yang pernah berperan secara historis sebagai pusat penampungan pegungsi dan pejuang pada Aksi Polisionil Belanda tahun 1947, selama 14 bulan.

\section{Perubahan Ruang}

Berdasarkan fungsinya, massa bangunan pada suatu tapak dari ke-sepuluh objek penelitian dapat diklasifikasikan menjadi 3 (tiga) jenis, yaitu griya ngajeng, griya wingking dan pawon. Konfigurasi antara griya ngajeng dan griya wingking adalah linear dari depan ke belakang. Susunan antara griya wingking dan pawon dapat diklasifikasikan menjadi 2 (dua), yaitu linear dari depan ke belakang atau sejajar dari kiri ke kanan (Gambar 4). 
Massa bangunan tambahan, umumnya terletak di halaman depan/latar ngarep, terdapat di rumah Mbah Lurah, yakni musholla umum yang dapat dimanfaatkan oleh warga desa. Di rumah Mbah Carik, terdapat massa bangunan kantoran untuk pelayanan administrasi warga desa. Rumah tokoh masyarakat (Mbah Guru), juga memiliki massa bangunan tambahan ruang kelas yang kemudian berubah fungsi menjadi ruang pertemuan PKK, sesuai dengan profesinya. Rumah buruh tani, hanya memiliki 2 (dua) jenis massa bangunan saja, yaitu griya wingking dan pawon. Ketiadaan massa bangunan griya ngajeng dahulu dipengaruhi oleh strata sosial.

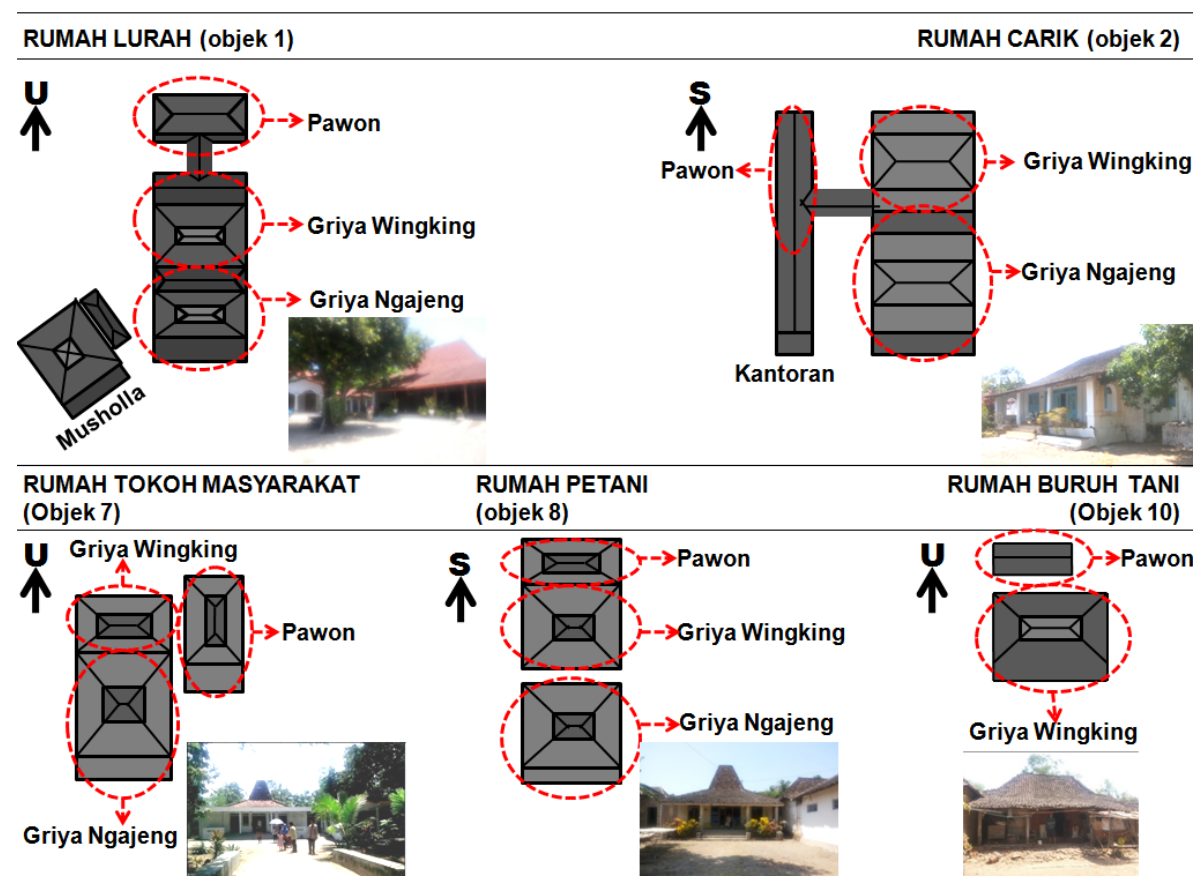

Gambar 4. Organisasi ruang/massa bangunan pada suatu tapak Sumber: hasil analisa, 2017

Sebuah rumah induk yang minimal tersusun atas 3 (tiga) massa bangunan ini, dikelilingi oleh halaman luas. Halaman tersebut terdiri atas latar ngarep di bagian depan, latar mburi di sisi belakang dan latar wetan serta latar kulon di samping. Latar ngarep/halaman depan berjarak ratarata 10 hingga $15 \mathrm{~m}$ dari tepi jalan, berfungsi untuk menjemur hasil panen. Latar mburi/halaman belakang yang luas untuk menempatkan sumur, jedhing-blandhong (kamar mandi), kakus (wc) dan pawuhan (tempat sampah), tegalan/kebun dan kandang. Halaman samping berupa latar wetan berada di sisi timur, sedangkan latar kulon di sisi barat, berfungsi untuk tegalan/kebun dan menempatkan blumbang/kolam ikan.

Susunan/konfigurasi dari sebuah rumah induk yang minimal terdiri atas 3 (tiga) massa bangunan, masih bertahan hingga kini, kecuali pada salah satu objek milik pamong desa/tokoh masyarakat, terjadi pemindahan massa bangunan griya ngajeng ke halaman samping (latar wetan) menjadi bagian dari rumah anaknya. Kini, penambahan massa bangunan untuk rumah anak-anak, terjadi di halaman samping (latar kulon dan/atau latar wetan). Penambahan massa bangunan rumah anak tidak pernah terjadi di halaman depan (latar ngarep) atau di belakang (latar mburi). Hal ini karena faktor kepercayaan agar mudah menangkap rezeki, sehingga masing-masing rumah di Desa Kaponan selalu mendapatkan akses ke jalan desa (Gambar 5). Perubahan organisasi ruang pada tapak dipengaruhi oleh perubahan struktur keluarga. 

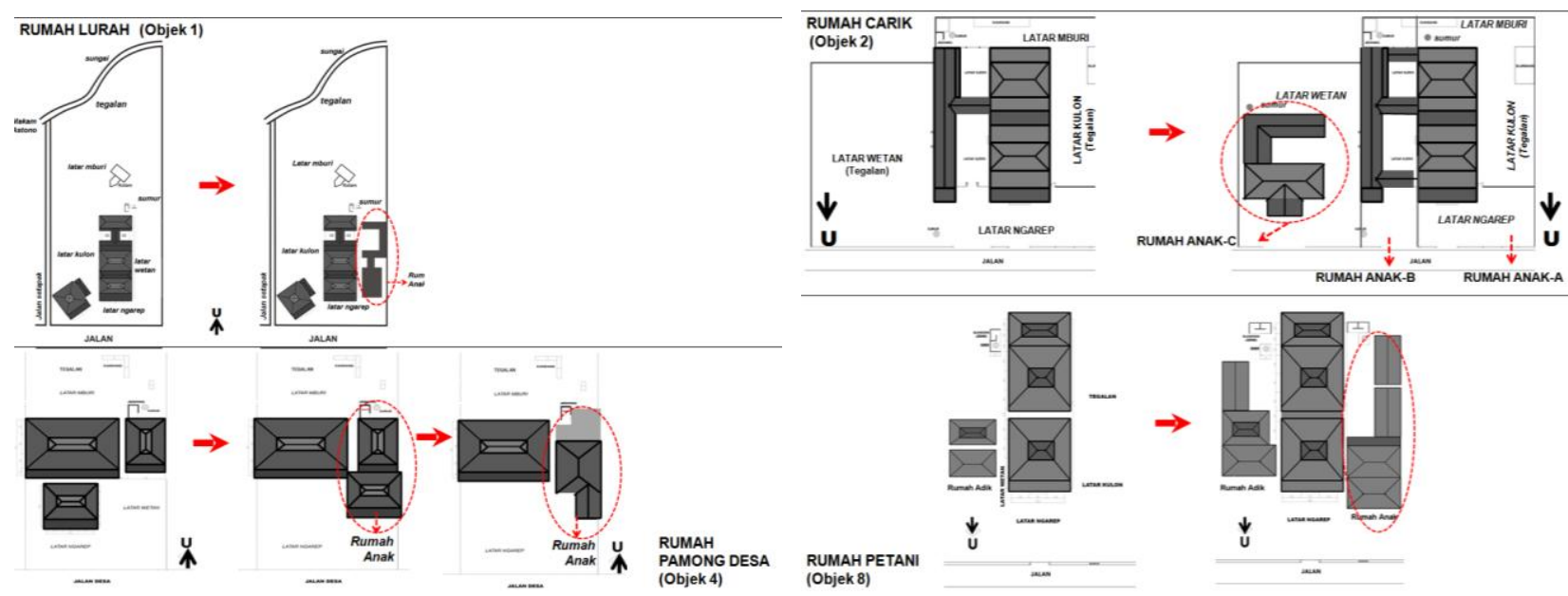

Gambar 5. Perubahan organisasi ruang/massa bangunan pada suatu tapak Sumber: hasil analisa, 2017

Griya ngajeng yang lengkap terdiri atas emper ngarep, pendopo dan pringgitan, dapat ditemui pada rumah pangreh praja dan tokoh masyarakat (Mbah Lurah, Mbah Carik dan Mbah Guru) yang menjabat pada masa lampau. Griya ngajeng sederhana, terdiri atas emper ngarep dan pendopo saja, disebut dengan omah kampung, dapat ditemui pada rumah para pamong desa, tokoh masyarakat dan petani kaya pada masa lalu (Gambar 6).

Konfigurasi dari emper ngarep, pendopo dan pringgitan adalah linear dari depan ke belakang dengan bentuk ruang simetris antara sisi kiri dan kanan yang seolah-olah dibagi oleh tiang-tiang/soko kayu di bagian tengahnya untuk mendukung atap limasan sinom, dorogepak atau bucu. Fungsi emper ngarep/teras sebagai tempat bersosialisasi kaum pria dengan para tetangga. Fungsi pendopo dahulu, sebagai ruang tamu di waktu pagi hingga petang, sedangkan pada malam hari untuk tidur anak-anak laki-laki. Fungsi pringgitan sebagai ruang transisi pada aktivitas harian atau tempat nanggap wayang ketika berlangsung hajatan. Khusus pada rumah Mbah Lurah dulu, griya ngajeng difungsikan sebagai balai desa untuk menampung musyawarah warga serta mewadahi aktifitas tradisi budaya seperti nanggap wayang pada puncak acara "bersih desa/upacara newu".

Terdapat perbedaan sirkulasi/akses masuk berdasarkan gender pada griya ngajeng di masa lampau, yaitu laki-laki melalui deretan pintu depan pendopo, sementara kaum hawa lewat pintu samping (kanan-kiri) bagian belakang pendopo. Kini, etiket tersebut sudah tidak berlaku lagi, karena perubahan lifestyle yang mengutamakan kepraktisan pada aktivitas kehidupan sehari-hari. Pintu samping-belakang pendopo, tidak lagi difungsikan, kecuali yang berhubungan dengan massa bangunan pawon/dapur. 


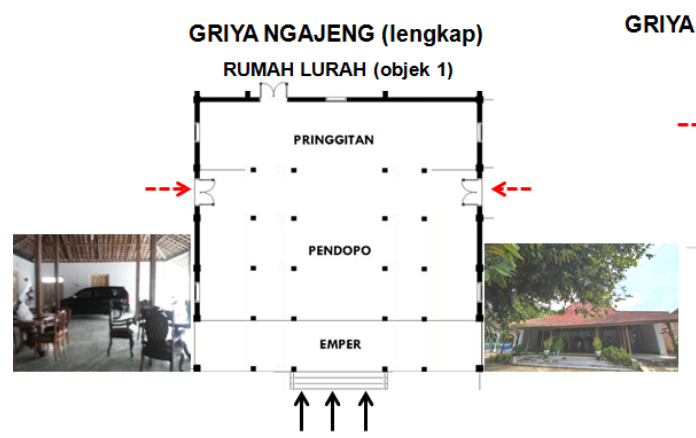

GRIYA NGAJENG (sederhana / Omah Kampung)

RUMAH PAMONG DESA (objek 3)
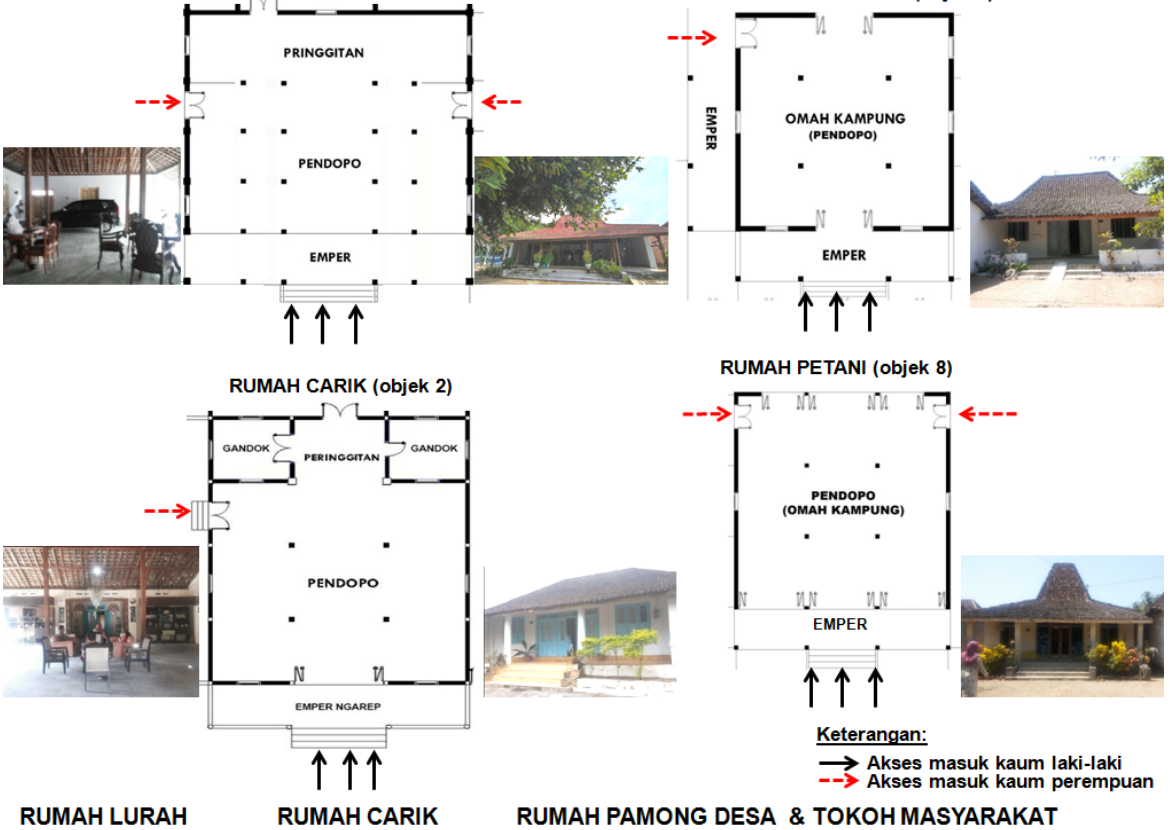

RUMAH PETANI (objek 8)
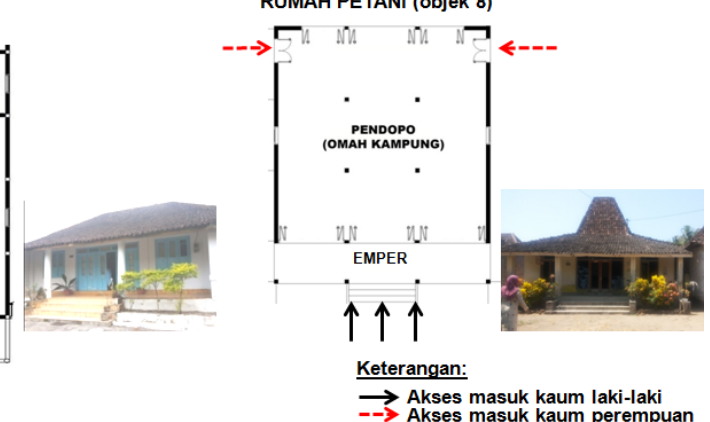

Keterangan: $\longrightarrow$ Akses masuk kaum laki-laki

RUMAH LURAH

RUMAH CARIK

RUMAH PAMONG DESA \& TOKOH MASYARAKAT
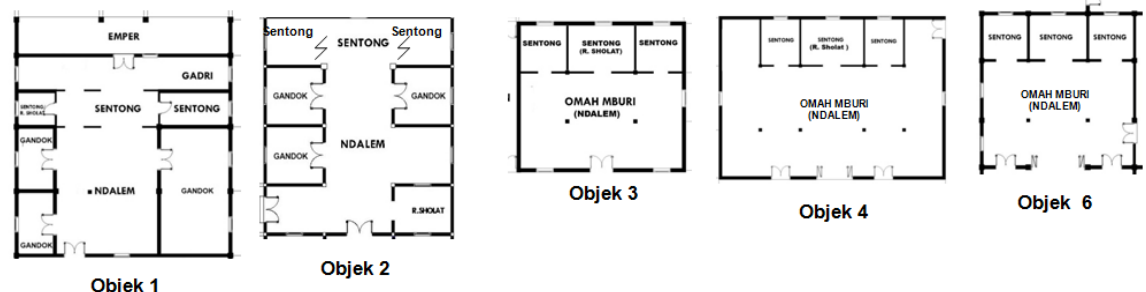

RUMAH PETANI RUMAH BURUH TANI

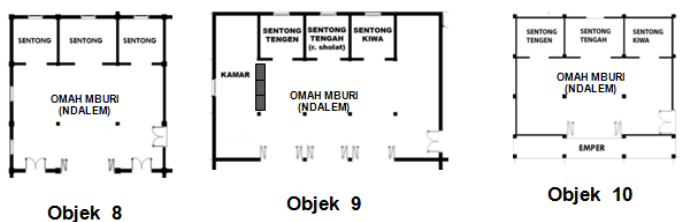

Gambar 6. Organisasi ruang pada griya ngajeng (atas) dan griya wingking (bawah) Sumber: hasil analisa, 2017

Perubahan organisasi ruang pada griya ngajeng dan griya wingking karena penambahan elemen ruang (dinding-pintu), telah menciptakan ruang-ruang baru. Bertambahnya jenis dan fungsi ruang di griya ngajeng serta griya wingking, terkadang membuat bentuk ruang tidak lagi simetris antara bagian kiri maupun kanan (Gambar 7). Sentong tengen yang merupakan ruang tidur orang tua dapat diperluas ke arah depan sesuai kebutuhan. Sentong kiwa yang menjadi ruang tidur bagi anak perempuan, dapat diperluas ke arah depan untuk menambah kamar-kamar baru, sesuai keperluan. Sekat antara sentong kiwa, sentong tengah dan sentong tengen, sekarang lebih permanen untuk menambah tingkat privasi. 

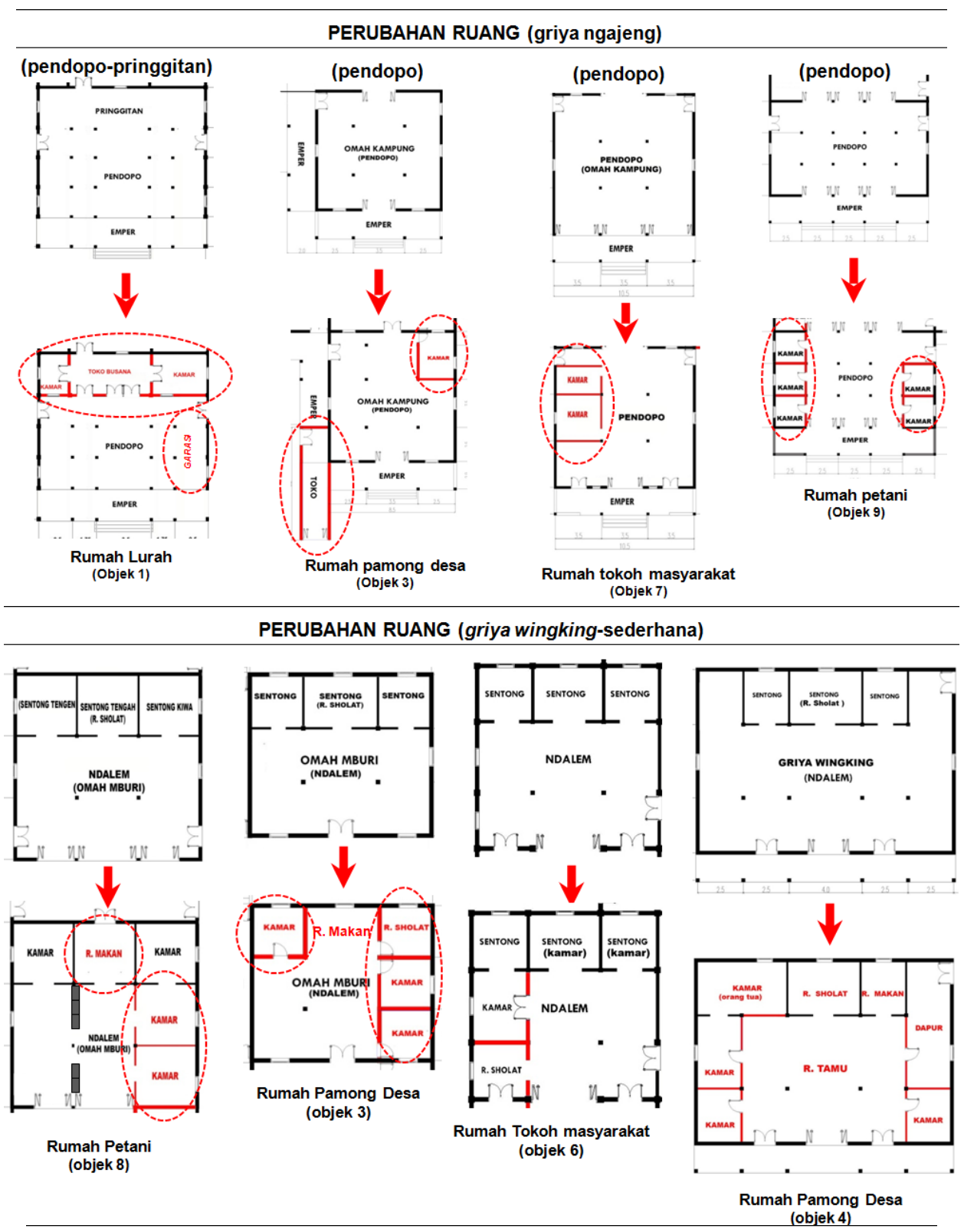

PERUBAHAN RUANG (griya wingking-lengkap)
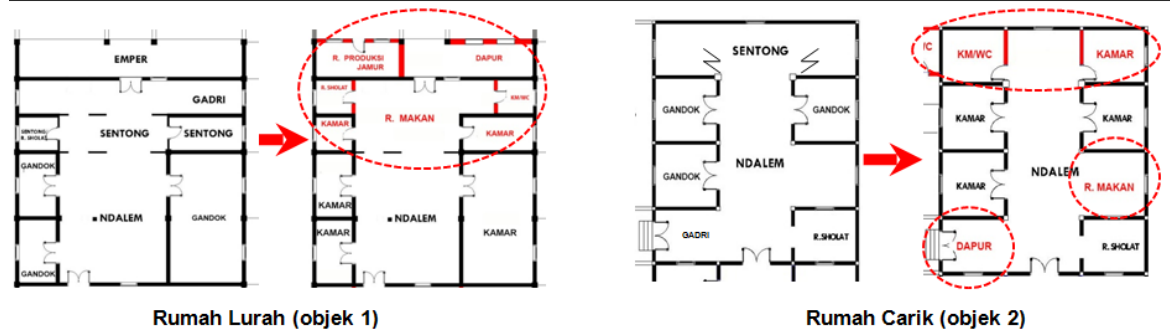

Gambar 7. Perubahan ruang pada griya ngajeng dan griya wingking Sumber: hasil analisa, 2017

Ruang-ruang baru umumnya difungsikan menjadi kamar tidur pengantin pada griya ngajeng, kemudian untuk menampung anak-anak yang telah berumah-tangga dan beranak-pinak. Ruang-ruang baru pada griya wingking umumnya difungsikan untuk mempertegas keberadaan ruang sholat dan 
menambah kamar-kamar bagi anak-anak yang telah beranjak dewasa, kemudian menampung para cucu. Perkembangan selanjutnya, anak-anak yang telah berumah tangga dan mandiri, menempati rumah baru di samping rumah induk atau berpindah ke luar desa/kota, sehingga kamar-kamar tersebut menjadi kosong, lalu berubah fungsi menjadi ruang belajar atau gudang penyimpanan pada aktivitas sehari-hari. Pada hari Lebaran, kamar-kamar tersebut kembali dipenuhi oleh saudarasaudara kandung yang mudik beserta anggota keluarganya

Penambahan ruang-ruang baru pada griya ngajeng dan griya wingking sebagai akibat perubahan struktur keluarga. Faktor lain yang mempengaruhi penambahan jumlah dan fungsi ruang tersebut, adalah perubahan struktur sosial, karena pemilik lama merupakan para pangreh praja atau tokoh masyarakat yang dahulu sering menerima banyak tamu. Ahli waris sekarang umumnya merupakan keluarga kecil yang berprofesi sebagai petani merangkap wirausahawan atau PNS merangkap petani/wirausahawan, sehingga pada beberapa objek penelitian terjadi perubahan fungsi ruang pada griya ngajeng untuk meningkatkan penghasilan/ekonomi, berupa ruang usaha/toko. Pada beberapa obyek penelitian menunjukkan adanya ruang-ruang servis di dalam griya wingking, seperti dapur dan km/wc, untuk menunjang kepraktisan gaya hidup modern.

Tata letak antara zona sakral (ruang sholat) dan area servis dibedakan berdasarkan hirarki (Gambar 8). Sisi barat yang merupakan arah kiblat memiliki hirarki lebih tinggi daripada oposisinya, yaitu timur. Sisi barat-depan dari griya wingking merupakan tempat untuk meletakkan ruang sholat karena sifatnya yang suci dan bersih. Ruang-ruang servis seperti pawon (dapur), jedhing (kamar mandi) dan sumur diletakkan pada sisi timur karena dianggap lebih kotor. Hal ini juga diterapkan dalam lingkup ruang mikro, seperti pada massa bangunan pawon. Pawon terdiri atas 3 (tiga) ruang tanpa sekat, meliputi ruang makan, tungku perapian dan tempat cuci piring. Ruang makan terletak paling barat, kemudian tungku api di bagian tengah dan tempat cuci piring berada paling timur. Tata letak berdasarkan hirarki ini masih bertahan hingga sekarang karena kuatnya pengaruh faktor kepercayaan warisan leluhur.

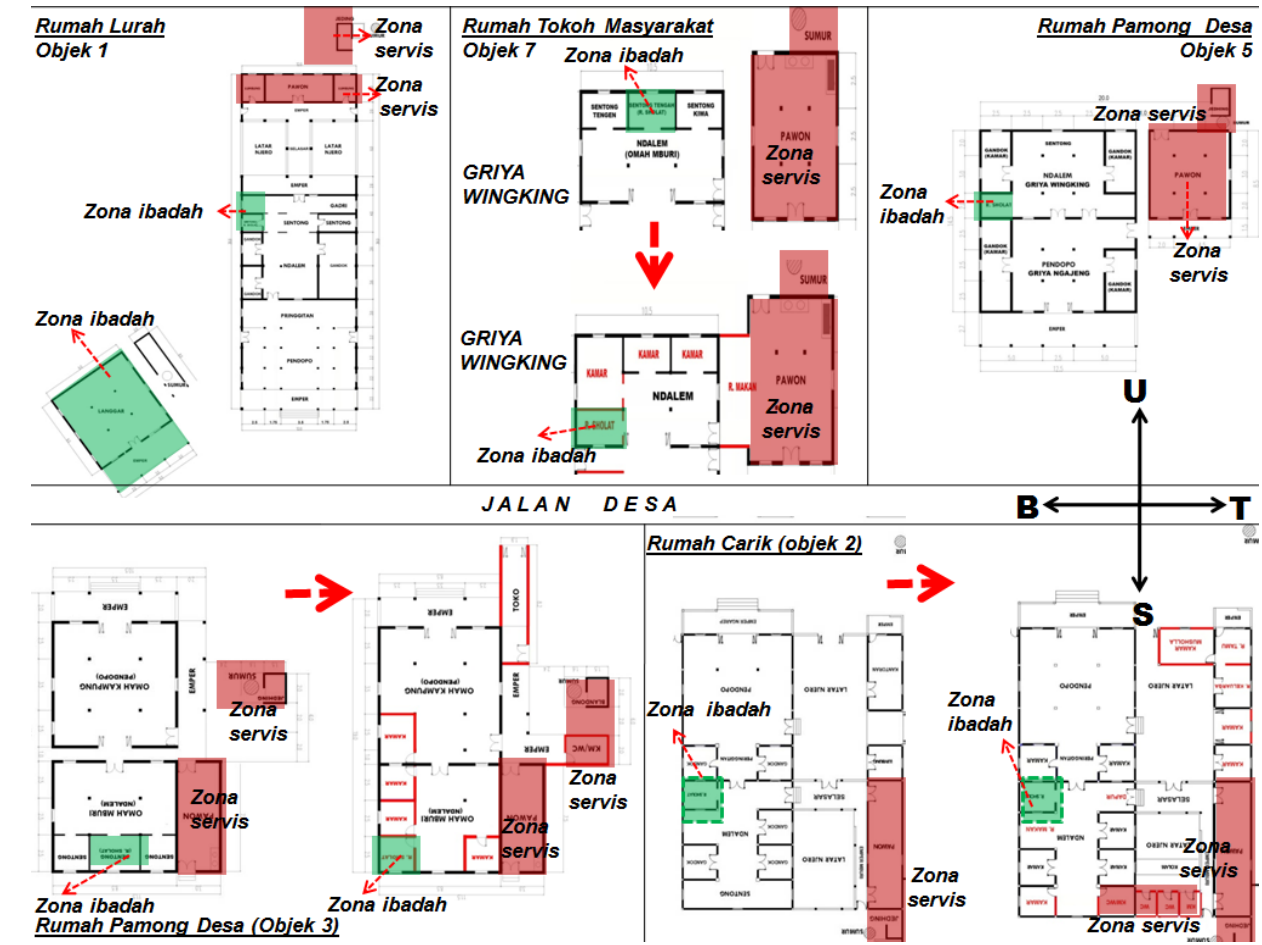

Gambar 8. Tata letak zona sakral (ruang sholat) dan area servis (pawon, jedhing, sumur) Sumber: hasil analisa, 2017 
Orientasi rumah-rumah di Desa Kaponan 95\% adalah ke utara atau selatan, baik itu yang berada di tepi jalan maupun di dalam gang kecil. Jalan-jalan di Desa Kaponan pun membujur dari barat ke timur. Hal ini berkaitan dengan kepercayaan yang dibawa oleh leluhur pendiri Desa Kaponan, hingga menjadi panutan bagi masyarakat sampai sekarang. Kepercayaan mengajarkan bahwa rumah rakyat yang jauh dari pusat pemerintahan/keraton adalah menghadap ke utara atau selatan. Keuntungan dari orientasi rumah ke utara atau selatan adalah dapat menangkap arah datangnya angin serta memperoleh kenyaman termal terhadap cahaya matahari.

Pergeseran teritori pemanfaatan ruang pada tradisi budaya temporer, yaitu "becekan", yang dahulu terjadi berdasarkan pemisahan gender dari depan ke belakang, kini menjadi dari kanan ke kiri atau sebaliknya (Gambar 9). "Becekan" merupakan tradisi budaya hajatan pengantin maupun sunatan, berasal dari kata "mbecek", artinya memberikan sumbangan bahan pangan atau hasil kebun kepada si empunya hajat untuk ditukar dengan masakan matang lengkap yang dibungkus daun pisang/jati. Ruang-ruang yang digunakan pada tradisi ini adalah griya ngajeng/pendopo (ruang tamu) dan latar ngarep (halaman depan), griya wingking/ndalem (ruang keluarga) dan latar wetan/kulon (halaman samping), pawon (dapur) serta latar njero (halaman dalam).

Dahulu, griya ngajeng/pendopo (ruang tamu) merupakan teritori khusus bagi tamu laki-laki yang dapat diakses melalui pintu depan. Griya wingking/ndalem (ruang keluarga) adalah ruang bagi tamu perempuan yang bisa diakses lewat pintu samping, setelah menyerahkan sumbangan di latar njero (halaman dalam) dan pawon (dapur). Sumbangan ini biasa dipikul oleh buruh tani yang diserahkan oleh istri pangreh praja maupun petani kaya kepada si-empunya hajat. Kini, tamu lakilaki dan perempuan ditempatkan di griya ngajeng/pendopo (ruang tamu) hingga latar ngarep (halaman depan) saja, sesuai dengan pergeseran posisi kuwade. Kuwade merupakan perlengkapan singgasana bagi pengantin, orang tua dan besan. Latar belakang kuwade adalah sekat sentong yang terbuat dari papan kayu berprofil atau ber-ornamen ukiran, lengkap dengan tirai. Posisi kuwade yang dulu berada di di depan sentong tengah pada griya wingking, kini bergeser semakin ke depan, bisa di pendopo atau emper ngarep demi memperoleh kepraktisan dan kelapangan ruang. Latar kuwade pun kini mudah diperoleh di biro jasa persewaan perlengkapan hajatan sedangkan sumbangan digantikan oleh sembako dan uang. Griya wingking kini menjadi ruang makan privat bagi keluarga dekat yang punya hajatan. Teritori ruang bagi para tetangga yang membantu si-empunya hajat (rewang) tetap berada di pawon (dapur) dan latar njero (halaman dalam). Dinamika teritori ruang pada tradisi "becekan" dipengaruhi perubahan gaya hidup modern yang mengutamakan kepraktisan.

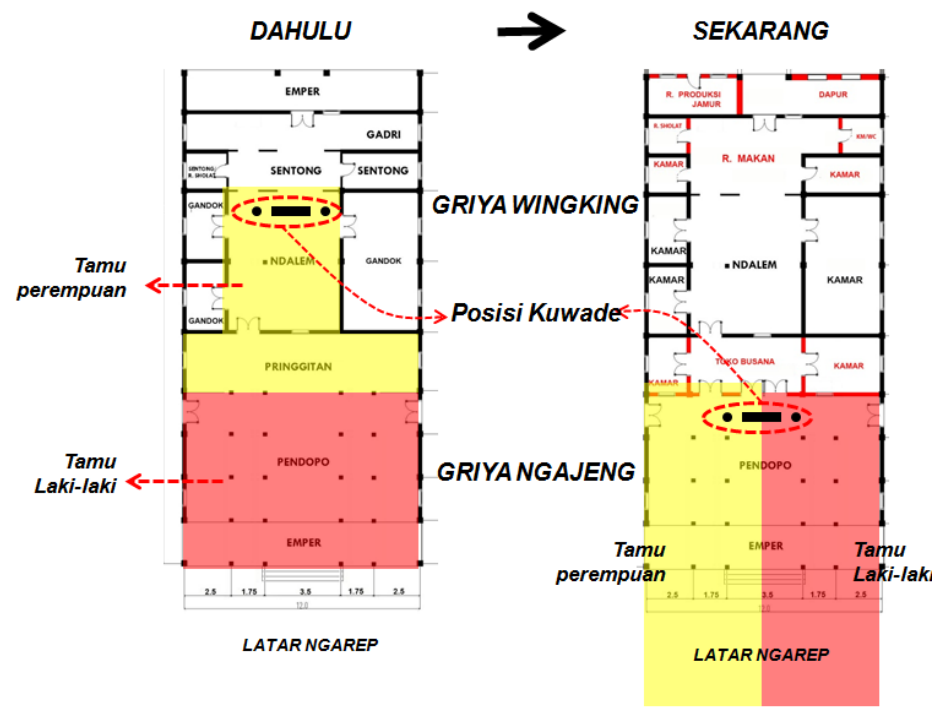

Gambar 9. Perubahan teritori ruang pada tradisi "becekan" Sumber: hasil analisa, 2017 
Pergeseran teritori pemanfaatan ruang pada tradisi religi "sejarah" Idul Fitri, terjadi berdasarkan hubungan kekerabatan (Gambar 10). Teritori ruang pada tradisi yang dilaksanakan di awal bulan Syawal ini tidak dibedakan berdasarkan gender. Dari dulu hingga sekarang, posisi duduk tuan rumah tetap berada di bagian belakang pendopo, yang berbeda adalah teritori ruang untuk para tamu. Dahulu, tamu-tamu yang merupakan saudara atau kerabat dekat, setelah bersalaman dengan tuan rumah langsung menuju ke ndalem di griya wingking, menunggu hingga waktu bersantap siang dengan menu daging kambing datang. Griya ngajeng/pendopo merupakan teritori ruang bagi tamutamu yang memiliki hubungan kerabat jauh, seperti tetangga satu dusun hingga satu desa, rombongan remaja masjid, karang taruna serta kenalan-kenalan dari luar desa. Perbedaan teritori ruang berdasarkan hubungan kekerabatan ini, terjadi karena tamu-tamu yang duduk di griya wingking memiliki durasi waktu kunjungan lebih lama dibandingkan dengan para tamu yang berada di griya ngajeng. Tradisi ini dapat berlangsung sepekan hingga berakhir pada hari ke-7 atau Bada Kupat.

Sekarang, teritori ruang yang digunakan berada di griya ngajeng/pendopo saja, tanpa membedakan hubungan kekerabatan. Kebiasaan masyarakat modern menjadikan durasi waktu berkunjung/bersilaturahmi semakin singkat. Keterbatasan waktu, banyaknya rumah yang hendak dikunjungi dan perubahan pola aktivitas menjadi alasan singkatnya waktu kunjungan. Kini, tradisi "sejarah" berlangsung rata-rata hanya 3 (tiga) hari saja. Susunan meja-kursi pada tradisi "sejarah" tidak mengalami perubahan dari dulu hingga sekarang, yaitu linear dari depan ke belakang, mengikuti lebar ruangan atau berderet sesuai arah utara-selatan (Gambar 10). Dinamika teritori ruang pada tradisi "sejarah" dipengaruhi oleh perubahan gaya hidup/lifestyle masyarakat sekarang yang cenderung praktis.

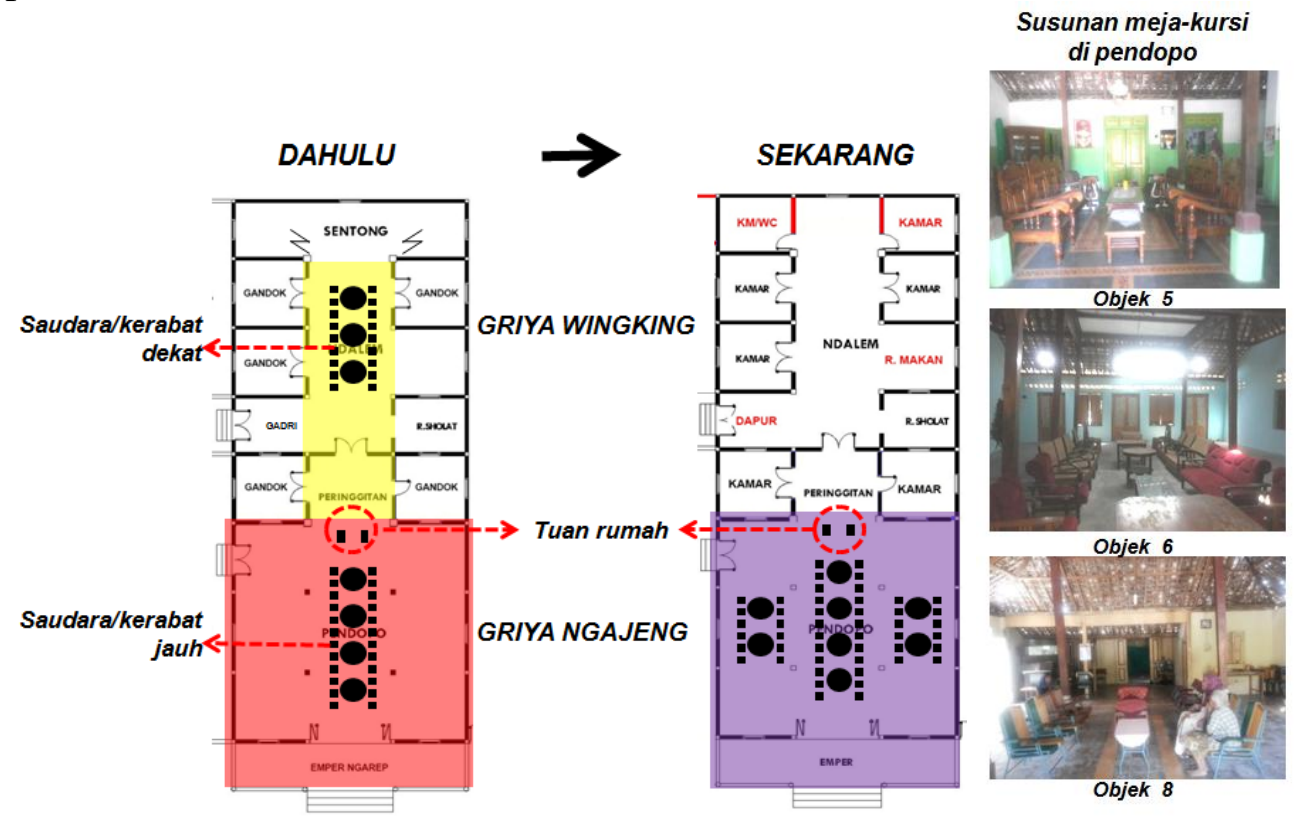

Gambar 10. Perubahan teritori ruang pada tradisi "sejarah"

Sumber: hasil analisa, 2017

\section{Kesimpulan}

Hasil penelitian menunjukkan bahwa bentuk, susunan/konfigurasi dan pola massa bangunan dalam suatu tapak yang minimal terdiri atas griya ngajeng, griya wingking dan pawon pada sebuah rumah tinggal Jawa Panaragan masih bertahan hingga kini. Faktor kepercayaan masyarakat Jawa (kejawen) mengenai keseimbangan makrokosmos dan mikrokosmos serta nilai-nilai yang diajarkan oleh leluhur mempengaruhi kesinambungan ini. Perubahan terjadi pada organisasi ruang dalam di 
griya ngajeng dan griya wingking berupa penambahan, pengurangan atau pemindahan elemen ruang yang meningkatkan jumlah, jenis dan fungsi ruang baru, terutama dipengaruhi oleh faktor struktur keluarga, yaitu bertambahnya jumlah anggota keluarga dan meningkatnya kebutuhan privasi. Alur sirkulasi yang dahulu dibedakan aksesnya berdasar ruang gender, kini tidak berlaku lagi akibat perubahan gaya hidup modern yang cenderung praktis.

Orientasi rumah dan pemisahan tata letak antara zona sakral/ruang ibadah dengan area servis berdasarkan hirarki masih bertahan, bahkan pada beberapa objek penelitian semakin dipertegas karena kuatnya faktor kepercayaan leluhur dan nilai-nilai spiritual.

Perubahan teritori pemanfaatan ruang pada pelaksanaan tradisi budaya "becekan" dan tradisi religi "sejarah", dipengaruhi oleh perubahan lifestyle pada zaman modern yang tidak lagi membedakan gender maupun hubungan kekerabatan, seiring meningkatnya pengetahuan/pendidikan.

\section{Daftar Pustaka}

Altman, I. \& Chemers M.M. (1989). Culture \& Environment. New York: Cambridge University Press.

Habraken, N. J. (1988(. Type as a Social Agreement. Makalah dalam Asian Congress of Architect. Seoul.

Habraken, N.J. (1982). Transformation of The Site. Massachusetts: MITT.

Kartono, J.L. (2005). Konsep Ruang Tradisional Jawa dalam Konteks Budaya. Jurnal Dimensi Interior. III (2): 124-136.

Marti, M, Jr. (1993). Space Operasional Analisis. USA:

PDA Publisher Corporation.

Rapoport, A. (2005). Culture, Architecture, and Design. Chicago: Locke Scientific.
Soegijono, Arkham, R, Zaenuri \& Setiantoro. (2006). Sekilas Sejarah Desa Kaponan dan Silsilah Penduduknya. Tidak dipublikasikan. Ponorogo.

Susilo, G.A. (2010). Peranan Arsitektur Tradisional Jawa dalam Pembangunan Berkelanjutan (Studi Kasus Arsitektur Joglo Ponorogo). Makalah dalam Seminar Nasional FTSP-ITN. Malang.

Susilo, G.A. (2015). Model Tipe Bangunan Tradisional Ponorogo. Makalah dalam Prosiding Tети Ilmiah IPLBI. E 137-E 144.

Sutarto A. \& Sudikan, S.Y. (Eds. ). (2004). Pendekatan Kebudayaan dalam Pembangunan Provinsi Jawa Timur.

Sutarto, A. (2004). "Studi Pemetaan Kebudayaan Jawa Timur" Jember: Kompyawisda. 